\title{
Take a deep breath: The relief effect of spontaneous and instructed sighs
}

\author{
Elke Vlemincx $^{\mathrm{a}, *}$, Joachim Taelman ${ }^{\mathrm{b}}$, Ilse Van Diest ${ }^{\mathrm{a}}$, Omer Van den Bergh ${ }^{\mathrm{a}}$ \\ ${ }^{a}$ Research Group on Health Psychology, Department of Psychology, University of Leuven, Belgium \\ b Biomedical Signal Processing Group, Department of Electrical Engineering, University of Leuven, Belgium
}

\section{A R T I C L E I N F O}

\section{Article history:}

Received 2 November 2009

Received in revised form 7 April 2010

Accepted 15 April 2010

\section{Keywords:}

Sighing

EMG

Respiratory variability

Mental stress

\begin{abstract}
A B S T R A C T
Spontaneous sighing is related to subjective relief of negative emotional states. Whether this also applies to instructed sighing is not known. The present study aimed to investigate sEMG and respiratory variability (1) during recovery from mental stress with and without an instructed sigh; (2) before and after spontaneous sighs throughout the experiment. A spontaneous sigh was preceded by increasing sEMG and increasing random respiratory variability, and followed by decreasing sEMG and increased structured correlated respiratory variability. Following an instructed sigh, a smaller reduction in SEMG and an increase in random respiratory variability during recovery from mental stress were observed. Thus, a spontaneous sigh seemed to induce relief. An instructed sigh appeared to inhibit recovery from mental stress.
\end{abstract}

(c) 2010 Elsevier Inc. All rights reserved.
Spontaneous breathing in healthy persons is characterized by substantial variability $[7,11,23,51,61]$, arising from various sources. Autonomic control processes, in response to perturbations, produce structured, time-dependent, deterministic, correlated, non-random breath-to-breath variations, returning respiration to its dynamic steady state in order to ensure system stability. Perturbations (e.g. through behavioral influences) elicit random variations in the respiratory system. Occasional random noise warrants system sensitivity; it trains the system in flexible and adaptive responding to perturbations so as to quickly return to a dynamic equilibrium $[18,46]$. As such, breathing shows considerable complexity and chaos resulting from neural control.

Respiratory centers in the brain stem include a rhythmogenic inspiratory network that generates a periodic rhythm consisting of specific spatiotemporal properties [13]. This rhythm-generating network, located in the pre-Bötzinger complex, functions as central rhythm and pattern generator defining amplitude and timing of respiratory bursts in the absence of feedback processes. This neural circuit is modulated both reflexively and behaviorally. Whereas brain stem structures control breathing through input of central and peripheral chemoreceptors and vagal afferents from pulmonary stretch receptors, contributing to ventilatory complexity $[15,26,36,37,44]$, behavioral control modulates this regulation through input from cortical structures [34,39].

Although occasional perturbations, e.g. through behavioral influences, are essential for effective breathing regulation, persistent perturbations will dysregulate breathing and compromise breath-to-

\footnotetext{
* Corresponding author.

E-mail address: elke.vlemincx@psy.kuleuven.be (E. Vlemincx).
}

breath variability, either by inducing excessive random variability (endangering respiratory stability), or by reducing variability (compromising sensitivity). In line with the former, increased random respiratory variability is found during resistive loading above the perception threshold [6], during induction of mental stress [54] and in panic disorder $[1,31,59,60,62]$. In line with the latter, respiratory variability is reduced during attention tasks [54] and during imagery of anxious scripts and in healthy subjects scoring high on trait negative affectivity [53]. These findings suggest that respiratory regulation and spontaneous respiratory variability can be compromised by behavioral influences overriding autonomic control.

Based on the theory of stochastic resonance [50,57], we hypothesize that adding noise to the respiratory system enhances respiratory control and restores a healthy balanced ventilatory variability. One such noise element may be a sigh. Consistent evidence supports the hypothesis that sighs operate as general psychophysiological resetters and serve regulatory functions [56]. First, sighing reduces hypoxia and hypercapnia [3,9] and restores gas exchange [9]. Second, findings show that sighing prevents atelectasis $[4,41]$ and restores lung compliance $[8,10,14,21,33,35]$. Third, sighs are abolished by vagotomy in cats [9,27], rats [3,21] and rabbits [19]. Moreover, through autonomic mechanisms a sigh increases bronchial and coronary blood flow and conductance [40]. Fourth, sighing resets parasympathetic control when sympathetic activity chronically dominates autonomic regulation [16]. Finally, sighing resets various fractions of respiratory variability to a healthy balance representing a sensitive, yet stable respiratory system: sighing resets respiratory short term memory and correlated respiratory variability $[2,56]$.

The above considerations may help to understand psychological correlates of sighing. First, sighing is related to relief: relief of dyspnea and perceived restlessness [22], relief of negative affect and craving 
during smoking withdrawal [32], and relief of stress [48,55]. Sighing may temporarily relieve tension (both psychologically and physiologically e.g. muscle tension) built up during negative emotional states characterized by too random breathing or during sustained psychological states characterized by a reduction of respiratory variability [54]. Second, excessive sighing is found in panic disorder patients, which may account for respiratory malfunction in this group, such as highly irregular breathing, low respiratory short term memory and low baseline $\mathrm{pCO}_{2}[1,31,45,58-60,62]$. Although occasional sighs reset respiratory properties and are related to subjective relief, this temporary relief effect may negatively reinforce sighing as a coping response with negative emotions. It follows that the more intense the negative emotions, the higher the reinforcement value, and the more chronic the negative emotions, the more frequently sighs will be reinforced. Excessive sighing or intentional sighing when physiologically inappropriate may dysregulate breathing, as it can be considered as excessive noise that prohibits the system to return to its steady state.

The purpose of the current experiment is to further study respiratory variability as related to spontaneous sighing and to instructed sighing following a negative emotional state. Mental stress was induced as negative emotion by means of mental arithmetic. Muscle tension is added as physiological parameter in order to investigate tension and relief related to sighing. Consistent evidence shows that muscle tension increases during mental stress evoked by mental arithmetic [24,29,30,38].

We predict that in response to an instructed sigh following mental stress excessive random variability will occur and muscle tension will recover less. In contrast, muscle tension is predicted to progressively increase before a spontaneous sigh and gradually decrease after a spontaneous sigh. Finally, we aim to replicate the finding that towards spontaneous sighs respiratory variability becomes increasingly random, whereas structured correlated respiratory variability strongly increases following spontaneous sighs.

\section{Method}

\subsection{Participants}

Forty-three undergraduates participated in the study (21 men, age 18-22). The experiment was approved by the Ethics Committees of the Department of Psychology and of the Faculty of Medical Sciences.

\subsection{Measures}

Breathing data were continuously collected by means of respiratory inductive plethysmography (RIP), using the LifeShirt System ${ }^{\circledR}$ (Vivometrics Inc., Ventura, CA). Two RIP transducers at the level of the rib cage and the abdomen, sewn into a LifeShirt garment including three accelerometers, were connected to the LifeShirt recorder, a digital processing unit including a data storage card.

Surface electromyography (sEMG) of the M. Trapezius pars descendens (TD), pars transversus (TT) and pars ascendens (TA) was measured using pre-gelled $\mathrm{Ag} / \mathrm{AgCl}$ contact electrodes (Nikomed, Denmark), attached according to European SENIAM (Surface ElectroMyoGraphy for the Non-Invasive Assessment of Muscles) recommendations and wired to a digital-analog converter unit (National Instruments, Austin, TX), sampled at $1000 \mathrm{~Hz}$ and digitised (24 bits) before stored on a personal computer.

\subsection{Procedure}

Participants were individually invited to an experiment studying physiological effects of mental arithmetics. Upon arrival, participants were informed on the course of the experiment and signed the informed consent. Then, the EMG electrodes were attached. Next, participants were instructed to perform three shoulder elevations separated by 1-min pauses to extract the maximal voluntary contraction (MVC) of the M. Trapezius pars descendens and reference voluntary contraction (RVC) of the M. Trapzius pars transversus and ascendens. Sitting on a low adjustable chair, participants performed the shoulder elevation for five seconds by lifting a handle with their hands on each side of the chair as high as possible with outstretched arms, without loading the low back muscles. Finally, they put on the LifeShirt garment and all sensors were connected to the LifeShirt recorder.

The experiment consisted of a 6-min baseline, followed by three task trials. Trials were presented in completely randomized order controlled by custom made stimulus presentation and data acquisition software Affect 4.0 [49]. Each trial contained a 6-min task phase followed by a 6 -min recovery phase. The three different tasks consisted of one sustained attention task, one mental arithmetic task and one mental arithmetic task followed by an explicit instruction to sigh. The baseline and the recovery phases involved watching a documentary ('The March of the Penguins'). This documentary exposed participants to neutral visual stimuli reducing boredom during baseline and recovery. Participants were ensured that no questions about the documentary would be asked later on and they could relax and enjoy watching the movie. The mental arithmetic task consisted of continuous mental calculations of sums of five operations with a two- or three digit number, which had to be performed without any verbalization (e.g. $361+7^{*} 2-4 / 2+13$ ). Participants used the mouse cursor to indicate the correct answer choosing between three alternatives, after which feedback was given. Participants were informed that at the end of the study the five best performing participants would be rewarded with a movie ticket. The experimenter was seated next to the participant. This mental arithmetic task was considered to be stressful as task difficulty was high, feedback was given, evaluation and rewards were given related to performance within time constraints and an observer was present $[5,17,25]$. The sustained attention task consisted of indicating the largest number of three alternatives using the mouse cursor. This attention task required the same motor movement (indicating the correct answer with the cursor), but it was not stressful: in contrast to the mental arithmetic task, task difficulty was extremely low, no time constraints were applied and no task evaluation or reward for performance was given. The instruction to sigh implied to sigh within the following 20-sec time window. Participants were asked to practice an instructed sigh, so that the experimenter could check whether participants understood and succeeded in executing the instructions. When necessary, the experimenter illustrated a sigh and the participants were asked to mimic this.

Before the experiment started, they were explicitely instructed again not to speak, mumble of move the lips, to sit comfortably, not to change posture and not to move, except for their dominant hand using the mouse cursor.

\section{Data analysis}

Analysis of respiratory and EMG measures towards and in response to spontaneous and instructed sighs will be reported here as main results. Findings on respiration and respiratory variability during the various phases of the experiment have been described extensively elsewhere [54]. The effects of mental stress on these measures and sEMG will be summarized in the results section.

\subsection{Parameter extraction}

\subsubsection{Respiration}

Editing of raw respiratory data was performed using Vivologic software (Vivometrics Inc., Ventura, CA). Two calibration procedures of the raw respiratory waveforms were carried out. First, the qualitative 
diagnostic calibration tool was used that automatically selects a 5-min period of regular breathing, during which relative gains in rib cage and abdominal RIP signals were verified. Second, the fixed volume calibration tool was used to calibrate the RIP sum signal in absolute volume units by comparison to an $800-\mathrm{ml}$ calibration bag. Four calibration trials, alternating sitting and standing, were run separated by $30-$ s pauses. In each trial, participants were asked to put on the nose clip and breathe rapidly in and out seven times filling and emptying an 800-ml calibration bag with each breath. The best fitting of two sitting calibration trials was chosen, since the experiment was run in sitting position. Next, to exclude movement artefacts, the accelerometers signals were checked in order to confirm that no changes in physical activity occurred. Finally, the following respiratory parameters were determined breath-by-breath: tidal volume (Vt), respiration rate ( $R R=60 /$ total breath time) and minute ventilation $(M V=V t \times R R)$. The coefficient of variation $(\mathrm{CV})$ of each respiratory parameter was computed as a measure of total respiratory variability, a compound of both correlated and random variability, whereas the autocorrelation (AR) at one breath lag was calculated as measure of structured, correlated respiratory variability.

\subsection{2. $E M G$}

The sEMG signals were analysed using Matlab 2008a (The Mathworks). The EMG signals of the left M. Trapezius are the signals of interest. Use of the mouse cursor during the tasks was performed with the dominant hand, which was the right hand for all participants, implying a possible influence on the muscle activity of the right Trapezius muscles. First, the sEMG data were rescaled relative to the MVC for the M. Trapezius pars descendens and the RVC for the M. Trapezius pars transversus and ascendens to make inter- and intrasubject comparisons possible. Both MVC and RVC were defined as the maximal electrical activity of the muscle during the three shoulder elevations for each muscle respectively. For further analysis, an amplitude measure correlated with the exerted force of the muscle was used and calculated in a window of 0.5 seconds. The root mean square (RMS) was chosen, being a statistical measure of the magnitude of a varying quantity which is especially useful when variates are positive and negative. Afterwards, the window was shifted one sample and thus forming a time series of the RMS measure.

\subsection{Statistical analysis}

Because of unreliable data acquisition, respiratory data from one participant and sEMG data from two participants were excluded from analysis. Next, respiratory variability and sEMG were analysed before and after one instructed sigh following mental stress. Averaged respiratory variability and sEMG were analysed preceding and following all spontaneous sighs in the experiment.

\subsubsection{Instructed sighs}

One of two mental arithmetic tasks was followed by a 20 -s instruction to sigh. Each participant performed a sigh within this 20-s time window, defined as a breath with a tidal volume at least two times as large as the mean tidal volume during the experiment. After recovery without instruction to sigh, a 20-s control period was selected that was considered as non-sigh period. When occasionally a spontaneous sigh occurred within this 20 -s time window, data preceding and following this non-sigh period were excluded from analysis.

First, to investigate the gradual transition of mental arithmetic to recovery with and without instructed sigh, three successive 2-min periods of the mental arithmetic task were compared to two successive 2 -min periods and a remaining 100 -s period of the recovery phase. (The $340 \mathrm{sec}$ in total started in both the recovery phases with and without instruction to sigh after the 20-s sigh or control period.) For each of these periods, measures of respiratory variability (CV(MV), $\mathrm{CV}(\mathrm{Vt}), \mathrm{CV}(\mathrm{RR})$, AR(MV), AR(Vt), AR(RR)) and average EMG (RMS(TD L), RMS(TA L) and
RMS (TT L)) were calculated, and subjected to a multilevel analysis with series (non-sigh vs. instructed sigh), phase (mental arithmetic vs. recovery) and period (1,2 and 3 ) as fixed predictors. Three contrasts, for which p-values were Bonferroni-corrected, were tested for each of these measures and considered significant at alpha level .016. First, Period 3 of mental arithmetic was compared with Period 1 of recovery following both a non-sigh and an instructed sigh. Next, recovery following a nonsigh was contrasted with recovery following an instructed sigh.

Second, in order to analyse more immediate effects of an instructed sigh, four blocks of 10 breaths were selected preceding the instructed sigh (at the end of mental arithmetic) and following the instructed sigh (during recovery with instruction to sigh). The same procedure was performed preceding a non-sigh (at the end of mental arithmetic) and following a non-sigh (during recovery with no instruction to sigh). The block number was considered as the distance to the instructed sigh or non-sigh: Block 1 was the first block preceding or following each instructed sigh or non-sigh. Between blocks was a $50 \%$ window overlap: the last 5 breaths of a block were the first 5 breaths of the next block. The non-sigh was considered as the first breath of the recovery phase when no instruction to sigh followed MT, and no spontaneous sigh occurred within the non-sigh period. Whenever a spontaneous sigh occurred in one of the blocks preceding or following the instructed sigh or non-sigh, all four blocks preceding or following the instructed sigh or non-sigh were excluded from analysis. Measures of EMG (mean RMS(TD L), RMS(TA L), RMS (TT L)) and respiratory variability (CV(MV), CV(Vt), CV(RR), AR(MV), $A R(V t), A R(R R))$ were calculated for each of these blocks, and subjected to a multilevel analysis with series (non-sigh vs. instructed sigh), phase (mental arithmetic vs. recovery) and block (1, 2, 3 and 4) as fixed predictors. The following contrasts were tested. First, all dependent variables were compared at Block 1 during mental arithmetic vs. recovery both following a non-sigh and an instructed sigh. Second, recovery periods following a non-sigh and following an instructed sigh were contrasted. P-values for this multiple contrast testing were considered significant at alpha level .016 using Bonferroni corrections.

\subsection{Spontaneous sighs}

Throughout the experiment spontaneous sighs within each phase of the experiment were defined as breaths with a tidal volume of at least 2 times as large as the mean tidal volume during this phase. In order to explore changes in EMG and respiratory variability preceding and following spontaneous sighs, 'sigh-series' were selected consisting of up to four blocks of 10 breaths preceding and following each spontaneous sigh. Between blocks was a 50\% window overlap. Whenever spontaneous sighs succeeded each other too quickly to select a full series of four blocks preceding and following a sigh, as many blocks possible following a sigh and preceding the next sigh were selected. In the remainder of the data, complete 'non-sigh-series' were selected consisting of four blocks preceding the non-sigh and four blocks following the non-sigh. As such, a non-sigh was a breath that was surrounded by at least eight blocks of breaths that were not included in the sigh-series. For each of these blocks, measures of EMG (mean RMS(TD L), RMS(TA L), RMS(TT L)) and respiratory variability (CV(MV), $\mathrm{CV}(\mathrm{Vt}), \mathrm{CV}(\mathrm{RR}), \mathrm{AR}(\mathrm{MV}), \mathrm{AR}(\mathrm{Vt}), \mathrm{AR}(\mathrm{RR})$ ) were obtained, and subjected to a multilevel analysis with series (non-sigh vs. spontaneous sigh), prepost (pre vs. post) and block (1, 2, 3 and 4) as fixed predictors. The block number was considered as the distance to the spontaneous sigh or non-sigh: Block 1 was the first block preceding or following each non-sigh and spontaneous sigh. Based on our hypotheses, the following comparisons were tested. For measures of respiratory variability a linear contrast (contrast coefficients: $-3 \quad-1 \quad 13$ ) across the four pre-blocks was tested for non-sigh series and spontaneous sigh series. In addition, Block 1 was compared pre and post in both the non-sigh and the spontaneous 
sigh-series. P-values for these multiple comparisons were Bonferronicorrected, resulting in an alpha level of .0125. For EMG measures a quadratic contrast (contrast coefficients: $-7-13553-1$-7) was tested across the eight blocks for non-sigh and spontaneous sigh-series, in order to investigate the predicted gradual increase in EMG preceding a spontaneous sigh and the gradual decrease in EMG following a spontaneous sigh.

\section{Results}

\subsection{The effect of mental stress on respiration, respiratory variability and} sEMG: a summary

Respiratory measures showed higher Vt (during the first mental arithmetic task), higher MV (during the first mental arithmetic task), increased RR, increased thoracic breathing and increased spontaneous sighing during mental arithmetic compared to baseline and recovery phases. Compared to baseline and recovery periods, respiratory variability measures showed that total respiratory variability was increased during mental arithmetic, whereas correlated variability was decreased during mental arithmetic, suggesting that random variability was higher during mental stress. Muscle tension as indicated by RMS(TT L) was higher at the end of the mental arithmetic task compared to the end of baseline. RMS(TA L) showed higher muscle tension at the end of the second mental arithmetic task compared to the end of baseline. No differences in muscle tension between the end of baseline and the mental arithmetic task were found for RMS(TD L).

\subsection{Instructed sighs}

\subsubsection{Phase analysis}

Phase analyses of respiratory variability and EMG following an instructed sigh compared to a non-sigh during recovery from mental arithmetic can be found in Table 1. A significant main effect of phase was found for all dependent variables, except for RMS(TA L), showing how both respiratory variability and EMG recovered after mental arithmetic: from mental arithmetic to recovery, $\mathrm{CV}(\mathrm{MV}), \mathrm{CV}(\mathrm{Vt})$ and $\mathrm{CV}(\mathrm{RR})$ decreased significantly, whereas AR(MV), AR(Vt) and AR(RR) increased significantly. RMS(TD L) and RMS(TT L) were significantly lower during recovery compared to mental arithmetic.

Looking more in detail to changes from the last mental arithmetic period to the first recovery period, both following an instructed sigh and a non-sigh, $A R(M V)$ and $A R(V t)$ increased significantly. Interestingly, only a significant increase in AR(RR) was found after a non-sigh and not following an instructed sigh. This result suggests that AR(RR) did not restore following mental arithmetic when a sigh was instructed. No differences were found between the last mental arithmetic period and the first recovery period for EMG measures.

When comparing recovery following an instructed sigh and a nonsigh, no differences were found, except for RMS(TT L). RMS(TT L) was significantly higher during recovery after an instructed sigh, compared to recovery when no sigh was instructed. This suggests that EMG did not return to baseline when a sigh was instructed.

\subsubsection{Block analysis}

Block analyses of respiratory variability and EMG following an instructed sigh compared to a non-sigh during recovery from mental arithmetic are shown in Table 2. Significant increases in CV(MV), CV (Vt) and CV(RR) were found from Block 1 at the end of mental arithmetic to Block 1 of recovery after an instructed sigh. No differences were found comparing Block 1 during mental arithmetic and recovery following a non-sigh. During recovery, $\mathrm{CV}(\mathrm{MV}), \mathrm{CV}(\mathrm{Vt})$ and $\mathrm{CV}(\mathrm{RR})$ was significantly higher following an instructed sigh compared to a non-sigh. No significant differences were found for AR, which suggests that an instructed sigh induces total respiratory variability which is not due to an increase in structured correlated variability. For EMG measures no significant changes were found.

\subsection{Spontaneous sighs}

Respiratory variability and EMG towards and following spontaneous sighs as opposed to non-sighs are described in Table 3. In addition, in the spontaneous sigh-series a significant linear contrast was found indicating a linear rise towards the sigh for CV(MV), CV(Vt) and CV (RR), which was not significant for $A R(M V), A R(V t)$ and $A R(R R)$. This result shows that the increase in respiratory variability preceding a spontaneous sigh was not due to structured correlated variability.

Table 1

Mean respiratory variability measures and EMG measures and statistical significance levels of the phase analysis comparing the effect of an instructed sigh with a non-sigh.

\begin{tabular}{|c|c|c|c|c|c|c|c|c|c|c|c|}
\hline \multicolumn{12}{|l|}{ Means } \\
\hline Series & Phase & Period & $\mathrm{CV}(\mathrm{MV})$ & $\mathrm{CV}(\mathrm{Vt})$ & $\mathrm{CV}(\mathrm{RR})$ & AR(MV) & $\mathrm{AR}(\mathrm{Vt})$ & AR(RR) & RMS(TD L) & RMS(TA L) & RMS(TT L) \\
\hline \multirow[t]{6}{*}{ Non-sigh } & \multirow[t]{3}{*}{ Mental arithmetic } & Period 1 & 23,44 & 34,42 & 17,39 & 0,15 & 0,07 & 0,10 & 0,0080 & 0,0295 & 0,0131 \\
\hline & & Period 2 & 22,43 & 30,87 & 17,82 & 0,07 & 0,00 & 0,08 & 0,0091 & 0,0291 & 0,0135 \\
\hline & & Period 3 & 24,44 & 35,17 & 17,56 & 0,05 & 0,01 & 0,07 & 0,0096 & 0,0334 & 0,0145 \\
\hline & \multirow[t]{3}{*}{ Recovery } & Period 1 & 22,76 & 25,90 & 14,34 & 0,19 & 0,10 & 0,20 & 0,0064 & 0,0342 & 0,0131 \\
\hline & & Period 2 & 17,96 & 21,30 & 13,07 & 0,12 & 0,10 & 0,15 & 0,0048 & 0,0324 & 0,0116 \\
\hline & & Period 3 & 18,98 & 25,31 & 12,98 & 0,16 & 0,08 & 0,15 & 0,0047 & 0,0300 & 0,0110 \\
\hline \multirow[t]{6}{*}{ Instructed sigh } & \multirow[t]{3}{*}{ Mental arithmetic } & Period 1 & 24,60 & 34,74 & 18,38 & 0,14 & 0,01 & 0,07 & 0,0073 & 0,0322 & 0,0139 \\
\hline & & Period 2 & 22,80 & 31,50 & 17,31 & 0,07 & $-0,01$ & 0,05 & 0,0080 & 0,0302 & 0,0143 \\
\hline & & Period 3 & 23,94 & 37,89 & 18,27 & 0,05 & $-0,02$ & 0,07 & 0,0087 & 0,0323 & 0,0149 \\
\hline & \multirow[t]{3}{*}{ Recovery } & Period 1 & 22,94 & 26,91 & 17,78 & 0,26 & 0,17 & 0,13 & 0,0076 & 0,0341 & 0,0140 \\
\hline & & Period 2 & 20,37 & 24,16 & 14,75 & 0,17 & 0,14 & 0,17 & 0,0071 & 0,0343 & 0,0132 \\
\hline & & Period 3 & 20,64 & 26,85 & 15,23 & 0,17 & 0,11 & 0,18 & 0,0069 & 0,0350 & 0,0132 \\
\hline \multicolumn{3}{|c|}{ Series $\mathrm{x}$ Phase $\mathrm{x}$ Period analysis } & $F(1,410)$ & $F(1,410)$ & $F(1,410)$ & $F(1,410)$ & $\mathrm{F}(1,410)$ & $F(1,410)$ & $F(1,388)$ & $F(1,388)$ & $F(1,388)$ \\
\hline \multicolumn{3}{|c|}{ Main effect of phase } & $9,26^{* *}$ & $34,22^{* * *}$ & $21,29^{* * *}$ & $23,3^{* * *}$ & $45,15^{* * *}$ & $24,36^{* * *}$ & $14,17^{* *}$ & 0,05 & $15,15^{* *}$ \\
\hline \multicolumn{12}{|c|}{ A priori contrasts } \\
\hline \multicolumn{3}{|c|}{ Recovery: Instructed sigh vs. Non-sigh } & 0,16 & 0,55 & 3,27 & 2,05 & 2,27 & 0,24 & 0,28 & 4,7 & $7,64^{*}$ \\
\hline \multicolumn{3}{|c|}{$\begin{array}{l}\text { Non-sigh: Mental arithmetic Period } 3 \\
\text { vs. Recovery Period } 1\end{array}$} & 0,13 & 5,52 & 2,53 & $8,39^{*}$ & $6,06^{*}$ & $8,24^{*}$ & 2,79 & 0,29 & 2 \\
\hline \multicolumn{3}{|c|}{$\begin{array}{l}\text { Instructed sigh: Mental arithmetic Period } 3 \\
\text { vs. Recovery Period } 1\end{array}$} & 0,27 & $9,85^{*}$ & 0,14 & $22,35^{* * *}$ & $25,32^{* * *}$ & 2,07 & 1,7 & 0,23 & 2,3 \\
\hline
\end{tabular}

Notes. ${ }^{*} \mathrm{p}<.016$ ( $\alpha$ Bonferroni-corrected), ${ }^{* *} \mathrm{p}<.001,{ }^{* * *} \mathrm{p}<.0001$.

Abbreviations used: CV (Coefficient of Variation), AR (autocorrelation), MV (minute ventilation), Vt (tidal volume), RR (respiration rate).

RMS (root mean square), TD L (left M. Trapezius pars descendens), TA L (left M. Trapezius pars ascendens), TT L (left M. Trapezius pars transversus). 
Table 2

Mean respiratory variability measures and EMG measures and statistical significance levels of the block analysis comparing the effect of an instructed sigh with a non-sigh.

\begin{tabular}{|c|c|c|c|c|c|c|c|c|c|c|c|}
\hline \multicolumn{12}{|l|}{ Means } \\
\hline Series & Phase & Block & CV(MV) & $\mathrm{CV}(\mathrm{Vt})$ & $\mathrm{CV}(\mathrm{RR})$ & AR(MV) & $\mathrm{AR}(\mathrm{Vt})$ & $\mathrm{AR}(\mathrm{RR})$ & RMS(TD L) & RMS(TA L) & RMS(TT L) \\
\hline \multirow[t]{8}{*}{ Non-sigh } & \multirow[t]{4}{*}{ Mental arithmetic } & Block 4 & 18,92 & 19,80 & 14,13 & 0,10 & 0,00 & 0,10 & 0,0052 & 0,0263 & 0,0131 \\
\hline & & Block 3 & 19,14 & 21,33 & 13,85 & 0,02 & 0,00 & $-0,03$ & 0,0048 & 0,0263 & 0,0127 \\
\hline & & Block 2 & 18,11 & 19,83 & 12,59 & 0,04 & $-0,04$ & $-0,01$ & 0,0048 & 0,0277 & 0,0128 \\
\hline & & Block 1 & 16,41 & 19,83 & 14,94 & 0,10 & 0,00 & 0,00 & 0,0050 & 0,0286 & 0,0130 \\
\hline & \multirow[t]{4}{*}{ Recovery } & Block 1 & 20,33 & 22,31 & 13,18 & 0,03 & 0,02 & $-0,02$ & 0,0063 & 0,0358 & 0,0144 \\
\hline & & Block 2 & 18,51 & 19,03 & 12,02 & 0,11 & 0,05 & $-0,03$ & 0,0060 & 0,0364 & 0,0143 \\
\hline & & Block 3 & 17,07 & 16,90 & 11,44 & 0,06 & $-0,09$ & $-0,01$ & 0,0063 & 0,0362 & 0,0136 \\
\hline & & Block 4 & 15,91 & 15,75 & 12,14 & $-0,06$ & $-0,13$ & 0,03 & 0,0064 & 0,0354 & 0,0130 \\
\hline \multirow[t]{8}{*}{ Instructed sigh } & \multirow[t]{4}{*}{ Mental arithmetic } & Block 4 & 17,70 & 20,04 & 15,93 & 0,09 & 0,06 & 0,00 & 0,0088 & 0,0229 & 0,0141 \\
\hline & & Block 3 & 16,11 & 16,90 & 14,34 & 0,00 & $-0,10$ & 0,01 & 0,0089 & 0,0230 & 0,0143 \\
\hline & & Block 2 & 17,69 & 18,09 & 13,13 & 0,05 & $-0,05$ & $-0,06$ & 0,0089 & 0,0221 & 0,0140 \\
\hline & & Block 1 & 19,23 & 20,41 & 14,53 & 0,04 & $-0,08$ & $-0,07$ & 0,0090 & 0,0224 & 0,0144 \\
\hline & \multirow[t]{4}{*}{ Recovery } & Block 1 & 30,87 & 31,77 & 23,91 & 0,08 & 0,07 & $-0,01$ & 0,0084 & 0,0348 & 0,0147 \\
\hline & & Block 2 & 19,99 & 21,28 & 14,34 & 0,01 & 0,03 & 0,00 & 0,0077 & 0,0344 & 0,0143 \\
\hline & & Block 3 & 16,82 & 18,84 & 12,92 & $-0,02$ & 0,01 & 0,01 & 0,0071 & 0,0358 & 0,0133 \\
\hline & & Block 4 & 16,10 & 18,13 & 12,92 & 0,02 & 0,07 & 0,05 & 0,0067 & 0,0374 & 0,0126 \\
\hline \multicolumn{3}{|c|}{ Series $\mathrm{x}$ Phase $\mathrm{x}$ Block analysis } & $\mathrm{F}(1,364)$ & $\mathrm{F}(1,364)$ & $\mathrm{F}(1,364)$ & $\mathrm{F}(1,364)$ & $\mathrm{F}(1,364)$ & $\mathrm{F}(1,364)$ & $\mathrm{F}(1,338)$ & $\mathrm{F}(1,338)$ & $\mathrm{F}(1,338)$ \\
\hline \multicolumn{12}{|c|}{ A priori contrasts } \\
\hline \multicolumn{3}{|c|}{$\begin{array}{l}\text { Instructed sigh Block } 1 \text { : Mental arithmetic } \\
\text { vs. Recovery }\end{array}$} & $55,88^{* * *}$ & $33,7^{* * *}$ & $45,12^{* * *}$ & 0,42 & 4,77 & 0,61 & 1,3 & 0,25 & 0,52 \\
\hline \multicolumn{3}{|c|}{ Non-sigh Block 1 : Mental arithmetic vs. Recovery } & 5,25 & 2,1 & 0,35 & 0,45 & 0,04 & 0,05 & 2,03 & 0,14 & 0,19 \\
\hline \multicolumn{3}{|c|}{ Recovery: Instructed sigh vs. Non-sigh } & $13,32^{* *}$ & $12,31^{* *}$ & $23,94^{* * *}$ & 0,14 & 5,36 & 0,25 & 1,22 & 3,49 & 1,75 \\
\hline
\end{tabular}

Notes. ${ }^{*} \mathrm{p}<.016$ ( $\alpha$ Bonferroni-corrected), ${ }^{* *} \mathrm{p}<.001,{ }^{* * *} \mathrm{p}<.0001$.

Abbreviations used: CV (Coefficient of Variation), AR (autocorrelation), MV (minute ventilation), Vt (tidal volume), RR (respiration rate).

RMS (root mean square), TD L (left M. Trapezius pars descendens), TA L (left M. Trapezius pars ascendens), TT L (left M. Trapezius pars transversus).

Comparing Block 1 before and after the spontaneous sigh showed a significant increase in $\mathrm{CV}(\mathrm{MV}), \mathrm{CV}(\mathrm{Vt})$ and $\mathrm{CV}(\mathrm{RR})$. Although no significant increases were found in $\mathrm{AR}(\mathrm{Vt})$ and $\mathrm{AR}(\mathrm{RR}), \mathrm{AR}(\mathrm{MV})$ was significantly higher after a spontaneous sigh compared to before, at Block 1 . This result suggests that increases in respiratory variability following a spontaneous sigh were due to increases in structured correlated variability. The above contrasts were specific to spontane- ous sighs, since no changes in respiratory variability were found in the non-sigh-series.

A quadratic trend was found for RMS(TT L) in the spontaneous sigh-series, which was not present for the non-sigh-series, showing how EMG gradually increased towards a spontaneous sigh and gradually decreased afterwards. The quadratic contrast was not significant for RMS(TD L) and RMS(TA L).

Table 3

Mean respiratory variability measures and EMG measures and statistical significance levels of the block analysis comparing the effect of spontaneous sighs with non-sighs.

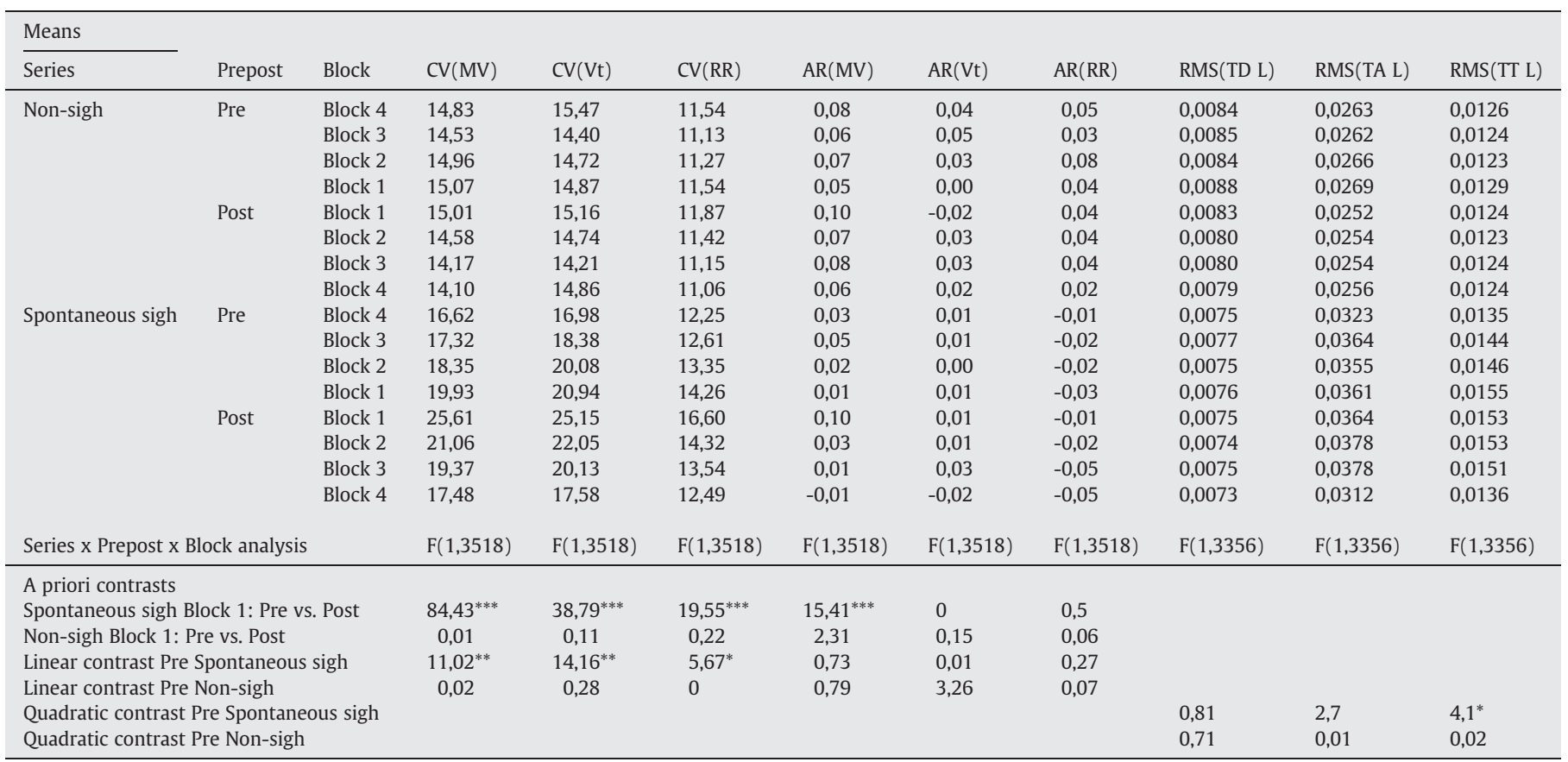

Notes. ${ }^{*} \mathrm{p}<.05,{ }^{* *} \mathrm{p}<.001,{ }^{* * *} \mathrm{p}<.0001$.

Abbreviations used: CV (Coefficient of Variation), AR (autocorrelation), MV (minute ventilation), Vt (tidal volume), RR (respiration rate).

RMS (root mean square), TD L (left M. Trapezius pars descendens), TA L (left M. Trapezius pars ascendens), TT L (left M. Trapezius pars transversus). 


\section{Discussion}

The aim of the present study was to investigate changes in respiratory variability and muscle tension (1) preceding and following spontaneous sighs and (2) following an instructed sigh after mental stress. Spontaneous sighs were preceded by increasing muscle tension and more random breathing and were followed by decreases in muscle tension and a resetting of structured correlated respiratory variability. Instructed sighing following mental stress, however, seemed to inhibit recovery of both muscle tension and respiratory variability.

The effects of spontaneous sighs on respiratory variability [56] were replicated: towards a spontaneous sigh respiratory variability becomes more random, after a spontaneous sigh structured correlated respiratory variability strongly increases. This finding suggests that towards a sigh respiratory regulation is dominated by behavior rather than autonomic control. Following a sigh, appropriate homeostatic control processes appear to be reset. Again, the resetting of structured correlated respiratory variability was specific to the parameter of minute ventilation, and did not apply to respiratory rate or tidal volume. This consistent finding fits the reasoning that respiratory variability represents regulation of gas levels in proportion to metabolic need. Since $\mathrm{pCO}_{2}$ levels are a direct function of minute ventilation, the product of both frequency and volume, it is plausible that the human body controls variability in frequency and/or volume, consistently affecting minute ventilation. The degree to which variability in frequency (or volume) is compensated for by volume (frequency) may dependent on subject characteristics and task properties.

Additionally, results show that muscle tension gradually increases towards a spontaneous sigh and gradually decreases in response to a spontaneous sigh. This finding supports the idea that sighing causes release of physiological and/or psychological tension and, therefore, is related to relief and might be used to cope with tension. Although increased sighing is found during various negative states, sighing is specifically associated to relief in aversive contexts causing tension. For example, during smoking withdrawal, which is a distressing and aversive experience, taking a single deep breath decreases negative affect and craving [32]. Additionally, both in rats and humans, sighing is associated with relief in a stressful context consisting of the successive anticipation and exposure to danger and safety stimuli [48,55].

These findings also relate to the physiological functions of sighing. First, progressive atelectasis and reductions in lung compliance or gas exchange efficiency might be associated with feelings of chest tightness and/or breathlessness that might be counteracted by a sigh, resulting in subjective relief. Second, in vitro studies have shown that the isolated rhythm-generating network generates distinct motor patterns, including eupnea and sighs, under influence of neuromodulators. This suggests that the rhythmogenic network can be dynamically reconfigured through chemical modulations into a functional spatial organization, such as sighs $[28,43,52]$. In line with this, in vivo chemical stimulation of the pre-Bötzinger complex elicits sighs or augmented breaths [47]. Also rat studies showing that this rhythmogenic network generates distinct volume-time relationships during eupneic breathing and during augmented breaths confirm the possibility of dynamic reconfiguration of neural networks [20]. This functional reconfiguration of eupnea into sighing appears to be chemically modulated by neuromodulators such as Substance $P$, which has been associated with stress and anxiety responses [12] and affective disorders [42]. This finding fits the reasoning that sighing regulates stress and/or anxiety.

Interestingly, this muscle tension relief effect of spontaneous sighs was found for the left $\mathrm{M}$. Trapezius pars transversus, suggesting that changes in muscle tension are not immediate effects of motor movement of the dominant right hand, but might be the result of alterations in mental activity. No changes were found in the pars descendens and ascendens. This could be explained by the finding that increased muscle tension during the mental stress task was most pronounced in the pars transversus.
Although opposite to the effect of spontaneous sighs, also the influence of an instructed sigh on EMG is revealed in the M. Trapezius pars transversus. Results show that muscle tension recovers less when a sigh is instructed after mental stress. In line with this finding, an instructed sigh increases total respiratory variability without changes in structured correlated respiratory variability, which suggests that an instructed sigh induces random variability. Moreover, comparison to recovery without imposing a sigh shows that random variability is highly disproportionate. In addition, structured correlated variability of respiration rate did not fully recover after an instructed sigh. That this result is particularly expressed in respiration rate could be explained by the finding that reductions in structured correlated variability during the mental stress task were most pronounced in this respiration rate parameter.

Multiple explanations can be formulated to interpret these findings. First, the instruction to sigh can be perceived as a task in itself. Although the specific instruction to sigh emphasized to do so whenever the participant felt appropriate and that more than sufficient time was provided, it may have been difficult for participants to estimate when it was appropriate for them to sigh. Future experimental designs could consider implementing a control task. Second, previous results have shown that sigh rate was strongly increased during this mental stress task [54]. Imposing additional sighing might have been physiologically inappropriate, because it could inhibit rather than enhance recovery. From a neurophysiological perspective, the switch from eupnea to instructed sighing is generated behaviorally instead of chemically, possibly leading to dysregulation instead of regulation. Assuming that the instructed sigh was physiologically unwarranted, the dysregulating effects of the instructed sigh are in line with the effects of excessive sigh rates on respiratory variability in panic disorder patients: disproportionate sighing induces random variability and reduces structured correlated variability. Because a spontaneous sigh relieves tension both physiologically and emotionally, sighing may become an intentional coping response to alleviate tension and to become relaxed through negative reinforcement. However, when applied excessively or in conditions that are physiologically inappropriate (i.e. when there is no severely reduced nor random breathing variability), sighing may be maladaptive.

The present study merely aimed to investigate the effects of an instructed sigh on respiratory variability and muscle tension in a laboratory context, and therefore no implications can reliably be derived for the application of breathing techniques in other contexts. Nevertheless, the current findings suggest the importance of research examining the effects of instructed deep breaths on relaxation, and the conditions underlying these effects. Various relaxation techniques make use of deep breathing exercises consisting of instructed, isolated deep breaths, with or without instructions of release of muscle tension (as in progressive muscle relaxation), instructions of heaviness and warmth (as in autogenic training), or instructions of awareness and attention (as in yoga and meditation). The efficacy of these relaxation techniques implies that the physiological state as well as the psychological context during which deep breaths are instructed may be critically important.

\section{References}

[1] Abelson JL, Weg JG, Nesse RM, Curtis GC. Persistent respiratory irregularity in patients with panic disorder. Biol Psychiatry 2001;49:588-95.

[2] Baldwin DN, Suki B, Pillow JJ, Roiha HL, Minnocchieri S, Frey U. Effects of sighs on breathing memory and dynamics in healthy infants. J Appl Physiol 2004;97: 1830-9.

[3] Bartlett D. Origin and regulation of spontaneous deep breaths. Respir Physiol $1971 ; 12: 230-8$.

[4] Bendixen HH, Smith GM, Mead J. Pattern of ventilation in young adults. J Appl Physiol 1964;19:195-8.

[5] Boiten FA, Frijda NH, Wientjes CJE. Emotions and respiratory patterns: review and critical analysis. Int J Psychophysiol 1994;17:103-28.

[6] Brack T, Jubran A, Tobin MJ. Effects of resistive loading on variational activity of breathing. Am J Respir Crit Care Med 1998;157:1756-63. 
[7] Bruce EN, Daubenspeck JA. Mechanisms and analysis of ventilatory stability. In: Dempsey JA, Pack AI, editors. Regulation of breathing. New York: Marcel Dekker; 1995. p. 285-313.

[8] Caro CG, Butler J, Dubois AB. Some effects of restriction of chest cage expansion on pulmonary function in man: an experimental study. J Clin Invest 1960;39:573-83.

[9] Cherniack NS, Euler C, Glowgowska M, Homma I. Characteristics and rate of occurrence of spontaneous and provoked augmented breaths. Acta Physiol Scand 1981;111:349-60.

[10] Davis GM, Moscato J. Changes in lung mechanics following sighs in premature newborns without lung disease. Pediatr Pulmonol 1994;17:26-30.

[11] Donaldson GC. The chaotic behavior of resting human respiration. Respir Physio 1992;88:313-21.

[12] Ebner K, Singewald N. The role of substance P in stress and anxiety responses. Amino Acids 2006;31:251-72.

[13] Feldman J, Del Negro CA. Looking for inspiration: new perspectives on respiratory rhythm. Nat Rev Neurosci 2006;7:232-42.

[14] Ferris BG, Pollard DS. Effect of deep and quiet breathing on pulmonary compliance in man. J Clin Invest 1960;39:143-9.

[15] Fiamma MN, Straus C, Thibault S, Wysocki M, Baconnier P, Similowski T. Effects of hypercapnia and hypocapnia on ventilatory variability and the chaotic dynamics of ventilator flow in humans. Am J Physiol Regul Integr Comp Physiol 2007;292: 1985-93.

[16] Franco P, Verheulpen D, Valente F, Kelmanson I, de Broca A, Scaillet S, et al. Autonomic responses to sighs in healthy infants and in victims of sudden infant death. Sleep Med 2003;4:569-77.

[17] Gaillard AWK, Wientjes CJE. Mental load and work stress as two types of energy mobilization. Work Stress 1994;8:141-52.

[18] Giardino ND, Lehrer PM, Feldman JM. The role of oscillations in self-regulation: their contribution to homeostasis. In: Kenney D, McGuigan FJ, editors. Stress and health: Research and clinical applications; 2000. p. 27-51.

[19] Glogowska M, Richardson JG, Widdicombe JG, Winning AJ. The role of the vagus nerves, peripheral chemoreceptors and other afferent pathways in the genesis of augmented breaths in cats and rabbits. Respir Physiol 1972;16:172-96.

[20] Golder FJ, Davenport PW, Johnson RD, Reier PJ, Bolser DC. Augmented breath phase volume and timing relationships in the anesthetized rat. Neurosci Lett 2005;373:89-93.

[21] Golder FJ, Reier PJ, Davenport PW, Bolser DC. Cervical spinal cord injury alters the pattern of breathing in anesthetized rats. J Appl Physiol 2001;91:2451-8.

[22] Hirose. Restlessness or respiration as a manifestation of akathisia: Five case reports of respiratory akathisia. J Clin Psychiatry 2000;61:737-41.

[23] Hughson RL, Yamamoto Y, Fortrat JO. Is the pattern of breathing at rest chaotic? A test of Lyapunov exponent. Adv Exp Med Biol 1995;393:15-9.

[24] Iwanaga K, Saito S, Shimomura Y, Harada H, Katsuura T. The effect of mental loads on muscle tension, blood pressure and blink rate. J Physiol Anthropol 2000;19: 135-41.

[25] Kelsey RM, Blascovich J, Leitten CL, Schneider TR, Tomaka J, Wiens S Cardiovascular reactivity and adaptation to recurrent psychological stress: The moderating effects of evaluative observation. Psychophysiol 2000;37:748-56.

[26] Khatib MF, Oku Y, Bruce EN. Contribution of chemical feedback loops to breath-tobreath variability of tidal volume. Respir Physiol 1991;83:115-28.

[27] Knowlton GC, Larrabee MG. A unitary analysis of pulmonary volume receptors. Am J Physiol 1946;147:100-14.

[28] Lieske SP, Thoby-Brisson M, Telgkamp P, Ramirez JM. Reconfiguration of the neural network controlling multiple breathing patterns: eupnea, sighs and gasps. Nat Neurosci 2000;3:600-7.

[29] Lundberg U, Forsman M, Zachau G, Eklöf M, Palmerud G, Melin B, et al. Effects of experimentally induced mental and physical stress on motor unit recruitment in the trapezius muscle. Work Stress 2002;16:166-78.

[30] Lundberg U, Kadefors R, Melin B, Palmerud G, Hassmén P, Engström M, et al. Psychophysiological stress and EMG activity of the trapezius muscle. Int J Behav Med 1994;1:354-70.

[31] Martinez JM, Kent JM, Coplan JD, Browne ST, Papp LA, Sullivan GM, et al. Respiratory variability in panic disorder. Depress Anxiety 2001;14:232-7.

[32] McClernon FJ, Westman EC, Rose JE. The effects of controlled deep breathing on smoking withdrawal symptoms in dependent smokers. Addict Behav 2004;29: 765-72.

[33] Mcllroy MB, Butler J, Finley TN. Effects of chest compression on reflex ventilatory drive and pulmonary function. J Appl Physiol 1962;17:701-5.

[34] McKay LC, Evans KC, Frackowiak RSJ, Corfield DR. Neural correlates of voluntary breathing in humans. J Appl Physiol 2003;95:1170-8.

[35] Mead J, Collier C. Relation of volume history of lungs to respiratory mechanics in anesthetized dogs. J Appl Physiol 1959;14:669-78.
[36] Mitsis GD, Governo RJM, Rogers R, Pattinson KTS. The effect of remifentanil on respiratory variability, evaluated with dynamic modeling. J Appl Physiol 2009;106:1038-49.

[37] Modarreszadeh M, Bruce EN. Ventilatory variability induced by spontaneous variations in $\mathrm{PaCO}_{2}$ in humans. J Appl Physiol 1994;76:2765-75.

[38] Nilsen KB, Sand T, Stovner LJ, Leistad RB, Westgaard RH. Autonomic and muscular responses and recovery to one-hour laboratory mental stress in healthy subjects. BMC Musculoskelet Disord 2007;8:81.

[39] Pattinson KTS, Mitsis GD, Harvey AK, Jbabdi S, Dirckx S, Mayhew SD, et al. Determination of the human brainstem respiratory control network and its cortical connections in vivo using functional and structural imaging. Neuroimage 2009;44:295-305.

[40] Porges WL, Hennessy EJ, Quail AW, Cottee DBF, Moore PG, McIlveen SA, et al. Heart-lung interactions: the sigh and autonomic control in the bronchial and coronary circulations. Clin Exp Pharmacol Physiol 2000;27:1022-7.

[41] Reynolds LB. Characteristics of an inspiration-augmenting reflex in anesthetized cats. J Appl Physiol 1962;17:683-8.

[42] Rozenkranz MA. Substance $P$ at the nexus of mind and body in chronic inflammation and affective disorders. Pyschol Bull 2007;133:1007-37.

[43] Ruangkittisakul A, Schwarzacher W, Secchia L, Ma Y, Bobocea N, Poon BY, et al. Generation of eupnea and sighs by a spatiochemically organized inspiratory network. J Neurosci 2008;28:2447-58.

[44] Sammon MP, Bruce EN. Vagal afferent activity increases dynamical dimension of respiration in rats. J Appl Physiol 1991;70:1748-62.

[45] Schwartz GE, Goetz RR, Klein DF, Endicott J, Gorman JM. Tidal volume of respiration and "sighing" as indicators of breathing irregularities in panic disorder patients. Anxiety 1996;2:145-8.

[46] Small M, Judd K, Lowe M, Stick S. Is breathing in infants chaotic? Dimension estimates for respiratory patterns during quiet sleep. J Appl Physiol 1999;86:359-76.

[47] Solomon IC, Edelman NH, Neubauer JA. Patterns of phrenic motor output evoked by chemical stimulation of neurons located in the pre-Bötzinger complex in vivo.J Neurophysiol 1999;81:1150-61.

[48] Soltysik S, Jelen P. In rats, sighs correlate with relief. Physiol Behav 2005;85: 589-602.

[49] Spruyt A, Clarysse J, Vansteenwegen D, Baeyens F, Hermans D. Affect 4.0: A free software package for implementing psychological and psychophysiological experiments. Exp Psychol 2010;57:36-45.

[50] Suki B, Alencar AM, Sujeer MK, Lutchen KR, Collins JJ, Andrade JS, et al. Life-support system benefits from noise. Nature 1998;393:127-8.

[51] Tobin MJ, Yang KL, Jubran A, Lodato RF. Interrelationship of breath components in neighboring breaths of normal eupneic subjects. Am J Respir Crit Care Med 1995; 152:1967-76.

[52] Tryba AK, Peña F, Lieske SP, Viemari JC, Thoby-Brisson M, Ramirez JM. Differential modulation of neural network and pacemaker activity underlying eupnea and sigh-breathing activities. J Neurophysiol 2008;99:2114-25.

[53] Van Diest I, Thayer JF, Vandeputte B, Van de Woestijne KP, Van den Bergh O. Anxiety and respiratory variability. Physiol Behav 2006;89:189-95.

[54] Vlemincx E, Taelman J, De Peuter S, Van Diest I, Van den Bergh O. Sigh rate and respiratory variability during mental load and sustained attention. Psychophysiology in press; doi:10.1111/j.1469-8986.2010.01043.x.

[55] Vlemincx E, Van Diest I, De Peuter S, Bresseleers J, Bogaerts K, Fannes S, et al. Why do you sigh? Sigh rate during induced stress and relief. Psychophysiology 2009;46:1005-13.

[56] Vlemincx E, Van Diest I, Lehrer PM, Aubert AM, Van den Bergh O. Respiratory variability preceding and following sighs: A resetter hypothesis. Biol Psychol 2010;84:82-7.

[57] Wiesenfield K, Moss F. Stochastic resonance and the benefits of noise: from ice ages to crayfish and squids. Nature 1995;373:33-6.

[58] Wilhelm FH, Gerlach AL, Roth WT. Slow recovery from voluntary hyperventilation in panic disorder. Psychosom Med 2001;63:638-49.

[59] Wilhelm FH, Trabert W, Roth WT. Physiologic instability in panic disorder and generalized anxiety disorder. Biol Psychiatry 2001;49:596-605.

[60] Wilhelm FH, Trabert W, Roth WT. Characteristics of sighing in panic disorder. Biol Psychiatry 2001;49:606-14.

[61] Wysocki M, Fiamma M-N, Straus C, Poon C-S, Similowski T. Chaotic dynamics of resting ventilatory flow in humans assessed through noise titration. Respir Physiol Neurobiol 2006;153:54-65.

[62] Yeragani VK, Radhakrishna RKA, Tancer M, Uhde T. Nonlinear measures of respiration: Respiratory irregularity and increased chaos of respiration in patients with panic disorder. Neuropsychobiology 2002;46:111-20. 